\title{
Is Urbanisation Rate a Feasible Supplemental Parameter in Forecasting Electricity Consumption in China?
}

\author{
Biao Yang, ${ }^{1}$ Yingcheng $\mathrm{Li}^{2}{ }^{2}$ Haokun Wei, ${ }^{3}$ and Huan $\mathrm{Lu}^{4}$ \\ ${ }^{1}$ School of Urban Planning and Management, Harbin Institute of Technology Shenzhen Graduate School, Shenzhen, \\ Guangdong 518055, China \\ ${ }^{2}$ The Bartlett School of Planning, University College London, London WC1E 6BT, UK \\ ${ }^{3}$ Research Institute of Electric Power Science of Shaanxi Electric Power Company, State Grid Corporation of China, Xian, \\ Shaanxi 710054, China \\ ${ }^{4}$ School of Tourism and Environmental Sciences, Shaanxi Normal University, Xi'an, Shaanxi 710119, China \\ Correspondence should be addressed to Yingcheng Li; yingcheng.li.14@ucl.ac.uk and Huan Lu; huanlu@snnu.edu.cn
}

Received 12 November 2015; Revised 29 December 2015; Accepted 30 December 2015

Academic Editor: Sergio Nardini

Copyright (c) 2016 Biao Yang et al. This is an open access article distributed under the Creative Commons Attribution License, which permits unrestricted use, distribution, and reproduction in any medium, provided the original work is properly cited.

\begin{abstract}
Traditional method of forecasting electricity consumption based only on GDP was sometimes ineffective. In this paper, urbanisation rate (UR) was introduced as an additional predictor to improve the electricity demand forecast in China at provincial scale, which was previously based only on GDP. Historical data of Shaanxi province from 2000 to 2013 was collected and used as case study. Four regression models were proposed and GDP, UR, and electricity consumption (EC) were used to establish the parameters in each model. The model with least average error of hypothetical forecast results in the latest three years was selected as the optimal forecast model. This optimal model divides total EC into four parts, of which forecasts can be made separately. It was found that GDP was only better correlated than UR on household EC, whilst UR was better on the three sectors of industries. It was concluded that UR is a valid predictor to forecast electricity demand at provincial level in China nowadays. Being provided the planned value of GDP and UR from the government, EC in 2015 were forecasted as $131.3 \mathrm{GWh}$.
\end{abstract}

\section{Introduction}

The consumption of electricity is largely related to the economic development, industrialisation, and urbanisation process in China for the past two decades. It is crucial for the local or provincial governments as well as electricity providers to forecast the demand of electricity in order to achieve better installation planning and administration. A common practical method widely applied by most of the electric power companies is using GDP planned by either central or local authorities as the predictor (or in other transforms, e.g., GDP growth rate in electricity elasticity coefficient method) to estimate the electricity demand for the next few years. The electricity consumption is likewise regarded as part of the economic development index system [1]. The rationale behind this practical approach is little more than the high correlation between electricity demand and GDP, regardless of the disagreement among past studies on their causality in academia [2-6].

The approach of forecasting electricity based on GDP had been functioning for many years for practical purposes but is being questioned after the appearance of two deviations between the growth rate of electricity consumption and growth rate of GDP in 1997-1998 and 2008 during the two global financial crises: the elasticity ratio of electricity consumption dropped below 0.6, as shown in Figure 1. Though there are some investigations sought to explain the deviations [7], the reasons behind it are yet to be clarified [8]. At the meantime, attention is being paid to the feasibility of using urbanisation rate as an additional predictor to forecast electricity demand for practical reasons. Here urbanisation rate refers to the percentage of the population living in urban 


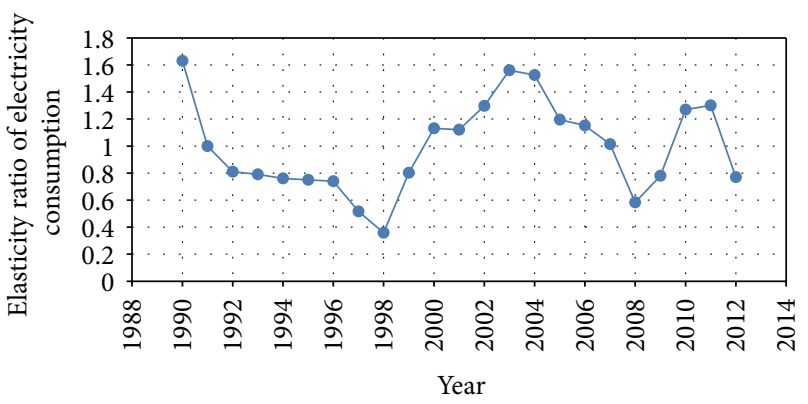

FIGURE 1: Elasticity ratio of electricity consumption from 1988 to 2012 [21].

areas as defined by national statistical offices, that is, ratio of urban population and total population.

In 1990s, the ways that urbanisation affects energy use in developing countries were discussed by Jones [9] and Imai [10]. After particularizing the factors and evidence on the influences of urbanisation on energy consumption, Jones reported a regression analysis on both modern and total energy, based on GDP per capita, urbanisation and industrialisation (defined as percentage of GDP coming from industry), using data extracted from 59 developing countries and regions for 1980. However, data of China was not included. The regression results indicate that $1 \%$ increase of urbanisation would correspond to an increase of modern energy consumption by $0.45 \%$ and $0.35 \%$ for total energy consumption. According to Jones [9], "modern" energy is also called "commercial" energy (including electricity and fossil fuels) which was being distinguished with "traditional" form of energy such as fuelwood, dung, and so forth. It was also found that the coefficient of urbanisation variable was more significant (95\% level) than that of industrialisation $(85 \%$ level). Imai [10] analysed the relationship between urbanisation and energy consumption per capita across 21 countries in the period of 1980-1993, with special attention on China. The worldwide results from regression analysis suggest that the cross-sectional correlation (adjusted $R^{2}>0.70$ ) between urbanisation and energy consumption is stable.

There are a few studies addressed on the relationship between urbanisation and total energy consumption [9-16], energy consumption of building [17], and transportation [18, 19]. However, the number of studies that identified electricity consumption from other forms of energy consumption is limited. The majority of such studies were dealing with the causality. Liddle and Lung [20] examined the causality between urbanisation and energy or electricity consumption using data of 105 countries (China included) from 1971 to 2009. These were reviewed from 21 past studies, of which seven were focused on electricity consumption. It seems that the stronger evidence was in favour of the causality direction from electricity consumption to urbanisation.

According to the results of past studies on urbanisation and energy, one could expect that correlation also exists between urbanisation and electricity, a dominating type of modern energy. This relationship since 2000 can be seen from Figure 2. In realistic situation, different forms of energy

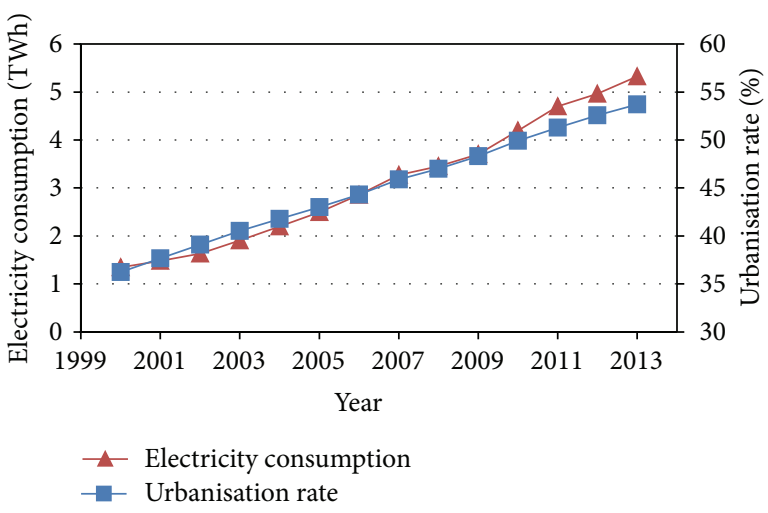

FIGURE 2: Electricity consumption and urbanisation rate of China from 2000 to 2013 [21].

are supplied separately by individual companies in China; for example, State Grid Corporation of China is specialised in electricity while China National Petroleum Corporation is specialised in petrol. Therefore, the individual companies are responsible for any surplus or deficiency if their plans of production are lack of accuracy. Moreover, the specific and practical administration of electricity planning and marketing is often run by provincial branches. Therefore it is worth exploring the feasibility of introducing urbanisation rate as an alternative or additional predictor, instead of using GDP only, to forecast electricity demand at provincial scale.

Although the utility industry of China is aware of ineffectiveness of GDP and thus in need of an improved approach to forecast electricity demand, literatures so far have not addressed this issue. Similar issues are present also in the forecasting of other energy sources, such as natural gas. The aim of this paper is to investigate to what extent urbanisation rate can be used as a parameter along with GDP, to provide better forecast on electricity demand in China at provincial scale. Empirical annual data of Shaanxi province was collected and used as a case study. Note also that the planned urbanisation rate for the next year or couple of years, similar to planned GDP, is available from authorities. The results are expected to provide better approaches to forecast electricity demand for power operators and stakeholders.

\section{Methodology}

2.1. Data. The historical data of electricity consumption, GDP, and urbanisation rate (worked out from urban population divided by total population) since 2000 was collected from past Shaanxi Statistical Yearbooks (see [22] for the latest 2013 version). Data before 2000 was excluded for consistency purpose because the population data by residence before 2000 were from the divisions of administrative areas; since 2000, the data has been estimated from national population census and annual national sample surveys on population changes.

Table 1 shows a summary of data collected for this study. Electricity consumption data is listed as four sectors: primary (1st), secondary (2nd), tertiary (3rd) industries and 
TABLE 1: Historical data of electricity consumption, GDP, and urbanisation rate in Shaanxi province from 2000 to 2013.

\begin{tabular}{|c|c|c|c|c|c|c|c|}
\hline \multirow{2}{*}{ Year } & \multicolumn{5}{|c|}{ Electricity consumption (108 Wh) } & \multirow{2}{*}{ GDP (CNY in billion) } & \multirow{2}{*}{ Urbanisation rate (\%) } \\
\hline & Total & $1 \mathrm{st}^{*}$ & $2 d^{*}$ & $3 \mathrm{rd}^{*}$ & Household & & \\
\hline 2000 & 292.76 & 22.90 & 198.44 & 38.11 & 33.31 & 180.4 & 32.27 \\
\hline 2001 & 321.54 & 25.11 & 214.87 & 45.81 & 35.77 & 201.1 & 33.62 \\
\hline 2002 & 355.97 & 26.45 & 237.51 & 52.12 & 39.89 & 225.3 & 34.63 \\
\hline 2003 & 393.68 & 35.84 & 266.97 & 56.97 & 43.91 & 258.8 & 35.54 \\
\hline 2004 & 477.03 & 28.70 & 334.60 & 66.02 & 47.71 & 317.6 & 36.35 \\
\hline 2005 & 516.00 & 31.10 & 358.09 & 71.46 & 55.35 & 393.4 & 37.24 \\
\hline 2006 & 580.72 & 34.39 & 406.03 & 78.25 & 62.06 & 474.4 & 39.12 \\
\hline 2007 & 653.69 & 36.02 & 463.61 & 88.72 & 65.76 & 575.7 & 40.61 \\
\hline 2008 & 708.02 & 37.64 & 497.65 & 97.33 & 75.41 & 731.5 & 42.09 \\
\hline 2009 & 740.11 & 38.09 & 504.34 & 108.30 & 89.38 & 817.0 & 43.49 \\
\hline 2010 & 859.22 & 39.13 & 589.51 & 116.25 & 112.38 & 1012.3 & 45.70 \\
\hline 2011 & 982.47 & 42.54 & 678.49 & 131.45 & 129.99 & 1251.2 & 47.29 \\
\hline 2012 & 1066.75 & 42.65 & 724.08 & 151.85 & 148.16 & 1445.4 & 50.02 \\
\hline 2013 & 1152.22 & 45.29 & 773.54 & 168.69 & 164.70 & 1604.5 & 51.31 \\
\hline
\end{tabular}

*Note: 1st, 2nd, and 3rd refer to primary/secondary/tertiary industries, respectively.

household, as the extent to which electricity consumption is correlated with GDP or urbanisation rate might be different depending on sectors. For example, the electricity consumption of primary industries including agriculture, forestry, and farming is expected to have better correlation with GDP for that part of electricity consumption is mainly used for productive purposes, whilst household electricity consumption might be more related to urbanisation rate because those urban households own more household electrical appliances than those in rural areas. Segmented historical GDP data in three industries sectors was not used because the planned segmented GDP is not available and thus cannot be used as forecast indicator.

2.2. Regression Models. GDP and urbanisation rate (UR) are two major independent variables in this study. The GDP refers to nominal GDP rather than real GDP; that is, any effects of inflation or deflation were ignored. This is mainly because it is the nominal GDP that is often announced by the authorities and thus can be used in forecast. Urbanisation rate is defined as the percentage of the urban population in the total population. Taking practical purposes and convenience into account, other parameters, such as population or electricity price, were not considered because the planned values of them are not available and thus cannot be used for forecasting.

As for the dependent variables, electricity elasticity coefficient is often used to evaluate the responsiveness of electricity consumption to the change of economic variables, for example, income (often in GDP) and price. The range of electricity elasticity coefficient for China varies with different stages of development and therefore was applied mainly in long-term scenarios at the national level as a macro index by governments and policy makers [3]. It should not be taken

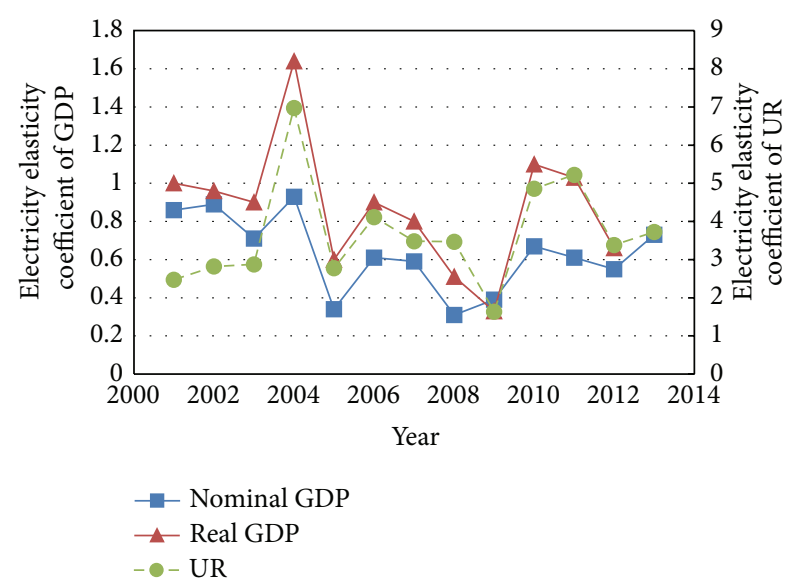

FIGURE 3: Electricity/GDP elasticity coefficient of Shaanxi province from 2001 to 2013.

for granted that such elasticity can also be used to forecast the electricity demand at the provincial scale in short-term.

Figure 3 demonstrates electricity elasticity coefficient of Shaanxi province from 2001 to 2013 (note that data of real GDP in 2013 was not available at the time the manuscript of this paper was submitted) for urbanisation rate (UR), nominal GDP growth, and real GDP growth from Table 1 . Apparent fluctuation can be observed as the differences of electricity elasticity coefficient of GDP between two adjacent years, for example, 2003-2004 and 2009-2010, were as large as $0.8-1.0$. Similar trend can be seen also in UR. The correlation coefficients between growth rates of electricity consumption and GDP/UR were found less than 0.4. The correlation coefficients between total electricity consumption and GDP/UR of Shaanxi per se, on the contrary, were greater than 0.98 . As a result, elasticity coefficient method is not recommended 
TABLE 2: Binary linear regression result of model (iii).

\begin{tabular}{lccccc}
\hline Predictor & $B$ & Std. error & Beta & $t$ & Significance \\
\hline $\mathrm{a}($ GDP) & 0.1285 & 0.008 & 0.22 & 1.703 & 0.117 \\
$\mathrm{~b}$ (UR) & 3557.4 & 589.801 & 0.78 & 6.032 & 0 \\
$\mathrm{c}$ (constant) & -883.63 & 189.574 & N/A & -4.661 & 0.001 \\
\hline
\end{tabular}

in this study to forecast electricity demand at provincial scale. Direct data in Table 1 will be used straightforwardly to perform the correlation and forecasting process.

2.3. Regression Models. Four linear regression models were used to explore the correlations between electricity consumption (EC) and GDP or urbanisation rate (UR):

$$
\begin{aligned}
& \operatorname{Model}(\mathrm{i}): \mathrm{EC}=\mathrm{a} \times \mathrm{GDP}+\mathrm{b} . \\
& \operatorname{Model}(\mathrm{ii}): \mathrm{EC}=\mathrm{a} \times \mathrm{UR}+\mathrm{b} . \\
& \text { Model (iii): } \mathrm{EC}=\mathrm{a} \times \mathrm{GDP}+\mathrm{b} \times \mathrm{UR}+\mathrm{c} . \\
& \text { Model (iv): } \mathrm{EC}=\mathrm{EC}_{1}+\mathrm{EC}_{2}+\mathrm{EC}_{3}+\mathrm{EC}_{\mathrm{h}}=\left(\mathrm{a}_{1} \times \mathrm{UR}\right. \\
& \left.+\mathrm{b}_{1}\right)+\left(\mathrm{a}_{2} \times \mathrm{UR}+\mathrm{b}_{2}\right)+\left(\mathrm{a}_{3} \times \mathrm{UR}+\mathrm{b}_{3}\right)+\left(\mathrm{a}_{\mathrm{h}} \times \mathrm{GDP}\right. \\
& \left.+\mathrm{b}_{\mathrm{h}}\right) .
\end{aligned}
$$

In models (i) and (ii), EC is, respectively, considered as a linear function of GDP only and UR only, that is, unary linear regression. In model (iii), EC is thought to be a linear function of both GDP and UR, that is, binary linear regression of GDP and UR. The relative weights of the two variables are $\mathrm{a}$ and $\mathrm{b}$ respectively. Model (iv) divides EC into four sectors: in primary $\left(\mathrm{EC}_{1}\right)$, secondary $\left(\mathrm{EC}_{2}\right)$, tertiary $\left(\mathrm{EC}_{3}\right)$ industries and household $\left(\mathrm{EC}_{\mathrm{h}}\right)$, so that the correlation between $\mathrm{EC}$ of each sector and GDP/UR can be checked separately, from which better forecast might be integrated. It was found that EC of three industries of Shaanxi province from 2000 to 2013 have a better correlation with UR than GDP; meanwhile the household EC was more relevant to GDP. Hence in model (iv), $\mathrm{EC}_{1}, \mathrm{EC}_{2}$, and $\mathrm{EC}_{3}$ will be forecasted according to UR, while $\mathrm{EC}_{\mathrm{h}}$ will be forecasted based on GDP. Note that other regression models (e.g., logarithmic, power, and exponential) were also explored. However $R^{2}$ were found in general no better than linear model on EC, GDP, and UR.

\section{Regression Results}

All unary linear regressions were performed in IBM SPSS Statistics 22.0. The best fit lines of regression analysis were drawn by minimising the sum of squared residuals. A residual means the difference between an observed value and the fitted value provided by the specific model. Results of the four linear regressions models were summarised below.

Figures 4 and 5 show the result of regression based on models (i) and (ii) with $R^{2}$ of 0.9804 (GDP) and 0.9942 (UR), respectively. Forecast can be made after these results by carrying out extrapolation on the best fit lines using planned GDP or UR of the following year(s).

Binary linear regression result of model (iii) was shown in Table 2. The value of $R^{2}(0.99544)$ indicates that GDP and UR together account for $99.54 \%$ of the variation in EC. It

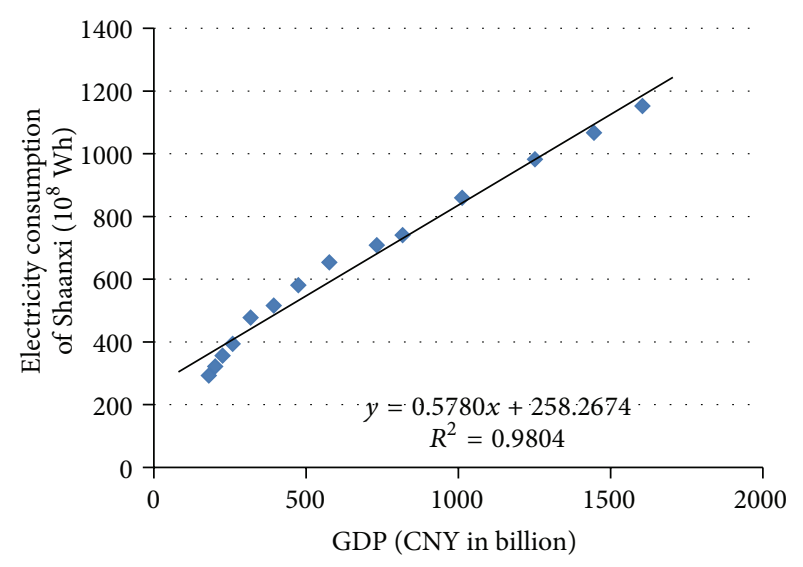

FIGURE 4: Unary linear regression result of model (i).

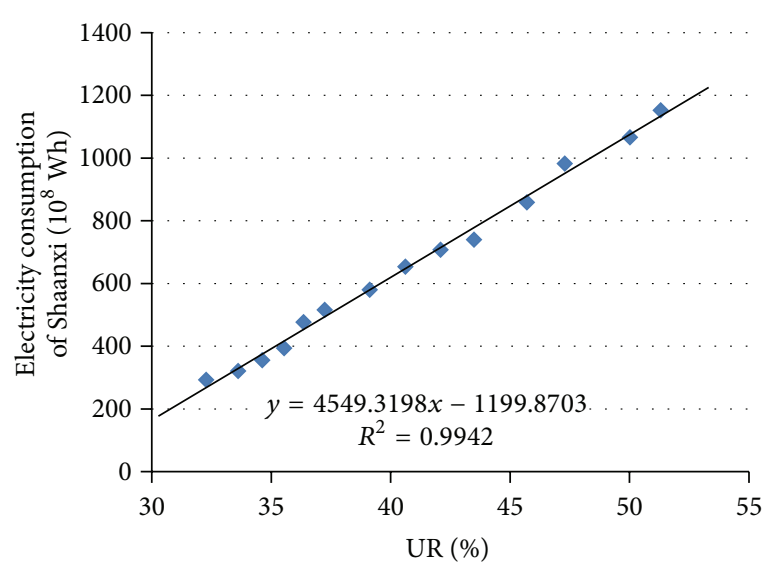

FIGURE 5: Unary linear regression result of model (ii).

can be seen from the Beta values that $\operatorname{UR}(\beta=0.78)$ is of more importance in model (iii) than GDP $(\beta=0.22)$. The significance of GDP ( $p=0.117)$ which is greater than 0.05 shows that, as a predictor, GDP is not making a significant contribution to model (iii). This also suggests that UR might be a more valid predictor of EC comparing with GDP. See also Figure 6 for 3D scatter plot and projection lines among GDP, UR, and EC.

Figure 7 illustrates the linear regression results of the four parts of total EC in model (iv). As discussed in Section 2.2, $\mathrm{EC}_{1}, \mathrm{EC}_{2}$, and $\mathrm{EC}_{3}$ were regressed by UR while $\mathrm{EC}_{\mathrm{h}}$ was regressed by GDP. The regression results suggest a high correlation with $R^{2}$ of $\mathrm{EC}_{2}, \mathrm{EC}_{3}$, and $\mathrm{EC}_{\mathrm{h}}$ greater than 0.99 . The coefficient of determination of $\mathrm{EC}_{1}$ and $\mathrm{UR}\left(R^{2}=0.88\right)$ is not as large as that of other parts but still a solid figure. 
TABLE 3: Summary of regression results for four proposed models.

\begin{tabular}{lc}
\hline Model & Regression results of models based on data of Shaanxi (2000-2013) \\
\hline Model (i) & EC $=0.0587 \times$ GDP +258.2674 \\
Model (ii) & EC $=4549.3198 \times$ UR -1199.8703 \\
Model (iii) & EC $=0.1285 \times \mathrm{GDP}+3557.4032 \times \mathrm{UR}-883.633$ \\
& $\mathrm{EC}=(105.7723 \times \mathrm{UR}-8.3064)+(3089.3848 \times \mathrm{UR}-809.9655)$ \\
Model (iv) & $+(648.605 \times \mathrm{UR}-172.9323)+(0.0900 \times \mathrm{GDP}+17.8137)$ \\
& $=3843.7629 \times \mathrm{UR}+0.0900 \times \mathrm{GDP}-973.3905$ \\
\hline
\end{tabular}

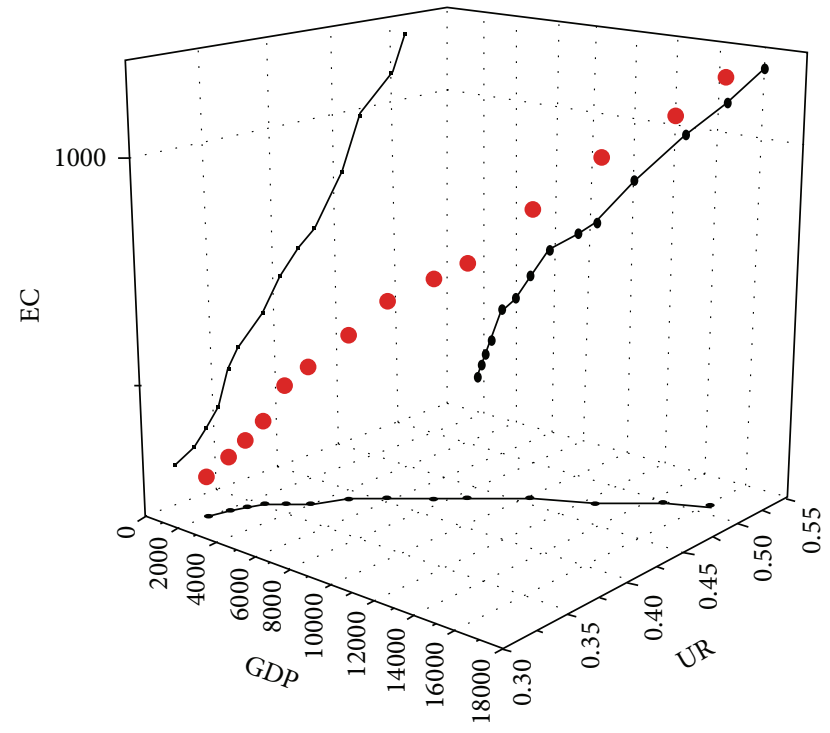

FIGURE 6:3D scatter plot and three projection lines among GDP, UR, and EC.

To summarise, the results of regression based on the proposed four models are listed in Table 3. It seems that all four regression models are feasible to be applied to EC forecasting. In order to give the optimal forecast, an optimal model needs to be selected from the four proposed models.

\section{Optimal Model and Forecasting Results}

4.1. Optimal Forecast Model Selection. The effectiveness of the above-mentioned four models in forecasting EC at provincial scale cannot be simply judged from their degrees of correlation only. In this section, hypothetical forecasts of EC in the latest three year (i.e., 2011-2013 in this paper) were performed assuming the data prior to that year is yet unknown. For example, hypothetical forecast of EC in 2012 will be worked out by extrapolating the regression model based on data from 2000 to 2011 . The model with least average error and sufficient consistency for the latest three years will be selected as the optimal forecast model.

See Table 4 for the errors of hypothetical forecast in 2011-2013 from models (i)-(iv). The details of calculation are omitted for that the process is straightforward (refer to Section 3). It can be seen that the errors (average $6.07 \%$ ) of
TABLE 4: Errors of hypothetical forecast in 2011-2013 based on prior data.

\begin{tabular}{lcccc}
\hline Model & 2011 & 2012 & 2013 & Average \\
\hline (i) & $6.87 \%$ & $6.83 \%$ & $4.50 \%$ & $6.07 \%$ \\
(ii) & $5.54 \%$ & $0.30 \%$ & $2.21 \%$ & $2.68 \%$ \\
(iii) & $5.46 \%$ & $2.20 \%$ & $0.68 \%$ & $2.78 \%$ \\
(iv) & $3.89 \%$ & $1.29 \%$ & $1.13 \%$ & $\mathbf{2 . 1 0} \%$ \\
\hline
\end{tabular}

TABLE 5: Predicators and forecast results of EC in 2014 and 2015.

\begin{tabular}{cccc}
\hline Year & Planned GDP & Planned UR & Forecasted EC (108 Wh) \\
\hline 2014 & 1750 billion & $53.123 \%$ & 1226.032 \\
2015 & 1920 billion & $55.000 \%$ & 1313.479 \\
\hline
\end{tabular}

model (i) were bigger than other models in any of the three years. The errors of models (ii) and (iii) varied from less than $0.5 \%$ to more than $5 \%$, with averages of $2.6-2.8 \%$. The errors of model (iv) stayed in the range of $1 \%-4 \%$ and with the least average $(2.10 \%)$, which met the criteria of optimal model. Hence, model (iv) was the optimal model and will be used to forecast EC for years 2014 and 2015. An additional advantage of model (iv) is that each part of EC will also be available.

4.2. Forecast Results of Optimal Model. In addition to model (iv) which has been selected as the optimal model, planned GDP and UR figures are also required to make forecast on EC. These figures at provincial scale are normally announced by the governments or local authorities in their work plan prior to the planned year. For years 2014 and 2015, the planned GDP of Shaanxi province were CNY 1750 and 1920 billion, respectively [23]. The UR was planned to be $55 \%$ at the end of 2015, according to the official "Shaanxi NewType Urbanisation Planning 2014-2020" report launched in September 2014 [23]. The planned UR of 2014 can therefore be interpolated between actual value of 2013 (51.31\%) and the planned value (55\%) of 2015 assuming the same growth rate of the two years. See Table 5 for the planned values and forecast results using the selected optimal regression model. Note that the forecasted EC in 2014 and 2015 were both calculated on the same formula based on data up to 2013 : $E C=3843.7629 \times$ $\mathrm{UR}+0.0900 \times \mathrm{GDP}-973.3905$. Thus, it was estimated that the electricity demand of Shaanxi province in 2014 and 2015 was, respectively, 122.6032 and 131.3479 GWh. According to the latest data reported by the Shaanxi local authority, the 

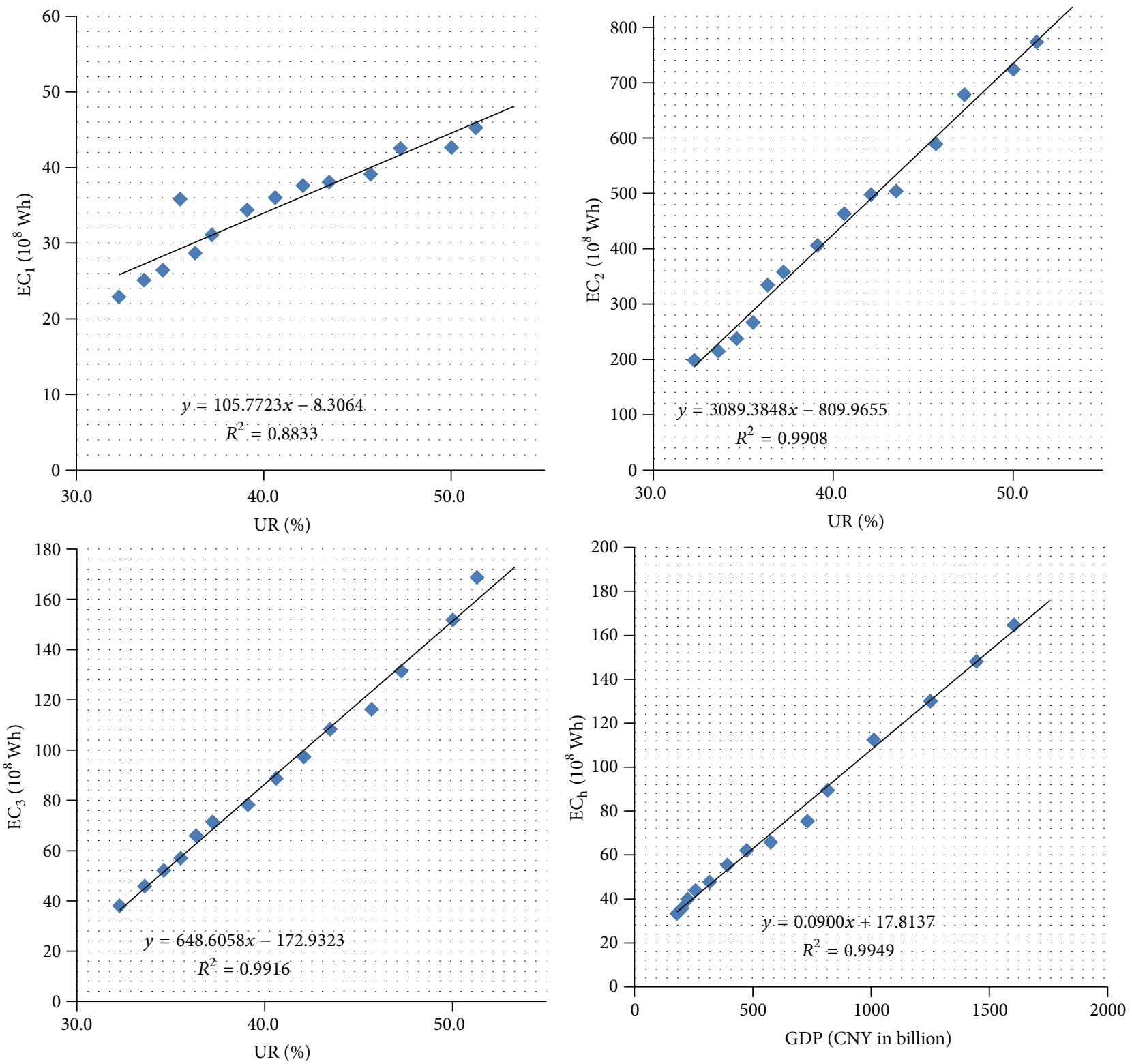

FIGURE 7: Linear regression results of four parts of $\mathrm{EC}$ in model (iv). $\mathrm{EC}_{1-3}$ were regressed with UR; $\mathrm{EC}_{\mathrm{h}}$ was regressed with GDP.

actual electricity consumption of 2014 was $122.601 \mathrm{GWh}$ (this figure was not available before this work is completed). The prediction error rate is less than $0.002 \%$. Better prediction of 2015 will be available with further data of actual GDP and UR in 2014.

\section{Conclusions}

In this study, urbanisation rate (UR) was introduced as a predictor to improve the electricity demand forecast based only on GDP in China at provincial scale. Four regression models were proposed and historical data of GDP, UR, and electricity consumption (EC) was used to establish the parameters in each model. The results of regressions based on data from 2000 to 2013 suggest that UR is a valid predictor to forecast EC at provincial scale. The model with least average error of hypothetical forecast results in the latest three years was selected as the optimal forecast model. This model divided total EC into sectors of industries and household parts, of which forecasts can be made separately using the better predictor of either GDP or UR. It was found that GDP was only better correlated than UR on household EC, whilst UR was better on the three sectors of industries. Being provided the planned value of GDP and UR from the government, forecasts of EC in 2014 and 2015 were obtained.

The forecasting process in this paper was aiming to provide an easy and highly adjustable tool for stakeholders to use. No discussion of causality between GDP, UR, and EC was included. The accuracy of forecast result is largely affected 
by the reliability of the planned figures and thus might be capped. The parameters of forecast model can be adjusted when the new historical data is available. More case studies from other provinces are needed to justify the feasibility of UR as predictor in forecasting EC in China.

\section{Conflict of Interests}

The authors declare that there is no conflict of interests regarding the publication of this paper.

\section{Acknowledgments}

The authors thank Zenghu Dang and Lifang Wu for their kind advice in the preparation of this paper.

\section{References}

[1] X. Song and Z. He, "The Keqiang index: a new benchmark for China's development," Social Indicators Research, vol. 123, no. 3, pp. 661-676, 2015.

[2] J. E. Payne, "A survey of the electricity consumption-growth literature," Applied Energy, vol. 87, no. 3, pp. 723-731, 2010.

[3] A. Shiu and P.-L. Lam, "Electricity consumption and economic growth in China," Energy Policy, vol. 32, no. 1, pp. 47-54, 2004.

[4] V. G. R. C. Govindaraju and C. F. Tang, "The dynamic links between $\mathrm{CO}_{2}$ emissions, economic growth and coal consumption in China and India," Applied Energy, vol. 104, pp. 310-318, 2013.

[5] M. J. Herrerias, R. Joyeux, and E. Girardin, "Short- and long-run causality between energy consumption and economic growth: evidence across regions in China," Applied Energy, vol. 112, pp. 1483-1492, 2013.

[6] B. Liddle and S. Lung, "Revisiting energy consumption and GDP causality: importance of a priori hypothesis testing, disaggregated data, and heterogeneous panels," Applied Energy, vol. 142, pp. 44-55, 2015.

[7] L. Zhang, J. Ruan, and J. Ding, "The institutional power shortage in China: capacity shortage or capacity under-utilisation?" Applied Energy, vol. 136, pp. 480-494, 2014.

[8] Y. S. Cheng, W. K. Wong, and C. K. Woo, "How much have electricity shortages hampered China's GDP growth?” Energy Policy, vol. 55, pp. 369-373, 2013.

[9] D. W. Jones, "How urbanization affects energy-use in developing countries," Energy Policy, vol. 19, no. 7, pp. 621-630, 1991.

[10] H. Imai, "The effect of urbanization on energy consumption," Journal of Population Problems, vol. 53, no. 2, pp. 43-49, 1997.

[11] Z. Jiang and B. Lin, "China's energy demand and its characteristics in the industrialization and urbanization process," Energy Policy, vol. 49, pp. 608-615, 2012.

[12] B. C. O’Neill, X. Ren, L. Jiang, and M. Dalton, “The effect of urbanization on energy use in India and China in the iPETS model," Energy Economics, vol. 34, supplement 3, pp. S339-S345, 2012.

[13] Y. Liu, "Exploring the relationship between urbanization and energy consumption in China using ARDL (Autoregressive Distributed Lag) and FDM (Factor Decomposition Model)," Energy, vol. 34, no. 11, pp. 1846-1854, 2009.

[14] R. Madlener and Y. Sunak, "Impacts of urbanization on urban structures and energy demand: what can we learn for urban energy planning and urbanization management?" Sustainable Cities and Society, vol. 1, no. 1, pp. 45-53, 2011.

[15] W. Zhou, B. Zhu, D. Chen, C. Griffy-Brown, Y. Ma, and W. Fei, "Energy consumption patterns in the process of China's urbanization," Population and Environment, vol. 33, no. 2-3, pp. 202-220, 2012.

[16] S. Wang, C. Fang, X. Guan, B. Pang, and H. Ma, "Urbanisation, energy consumption, and carbon dioxide emissions in China: a panel data analysis of China's provinces," Applied Energy, vol. 136, pp. 738-749, 2014.

[17] B. Li and R. Yao, "Urbanisation and its impact on building energy consumption and efficiency in China," Renewable Energy, vol. 34, no. 9, pp. 1994-1998, 2009.

[18] P. Poumanyvong, S. Kaneko, and S. Dhakal, "Impacts of urbanization on national transport and road energy use: evidence from low, middle and high income countries," Energy Policy, vol. 46, pp. 268-277, 2012.

[19] M. Zhang, H. Mu, G. Li, and Y. Ning, "Forecasting the transport energy demand based on PLSR method in China," Energy, vol. 34, no. 9, pp. 1396-1400, 2009.

[20] B. Liddle and S. Lung, "Might electricity consumption cause urbanization instead? Evidence from heterogeneous panel longrun causality tests," Global Environmental Change, vol. 24, no. 1, pp. 42-51, 2014.

[21] National Bureau of Statistics of China, China Statistical Yearbook 2013, China Statistics Press, Beijing, China, 2013.

[22] Statistical Bureau of Shaanxi Province, Shaanxi Statistical Yearbook 2013, China Statistics Press, Beijing, China, 2013.

[23] The People's Government of Shaanxi Province, Shaanxi NewType Urbanization Planning 2014-2020, 2014. 


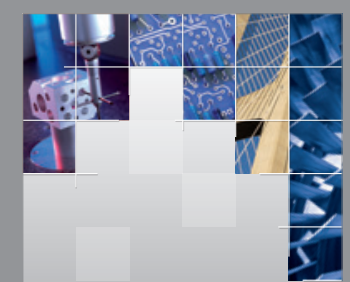

\section{Enfincering}
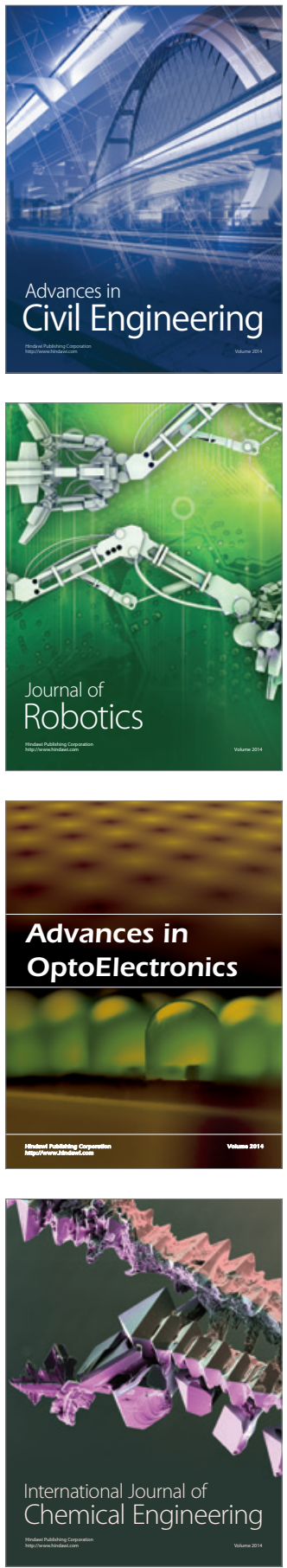

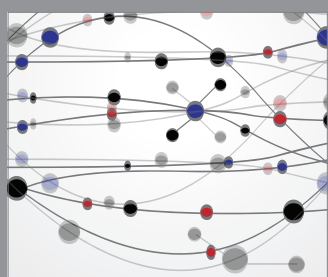

The Scientific World Journal

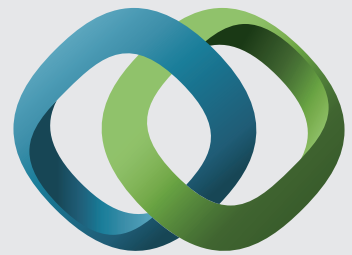

\section{Hindawi}

Submit your manuscripts at

http://www.hindawi.com
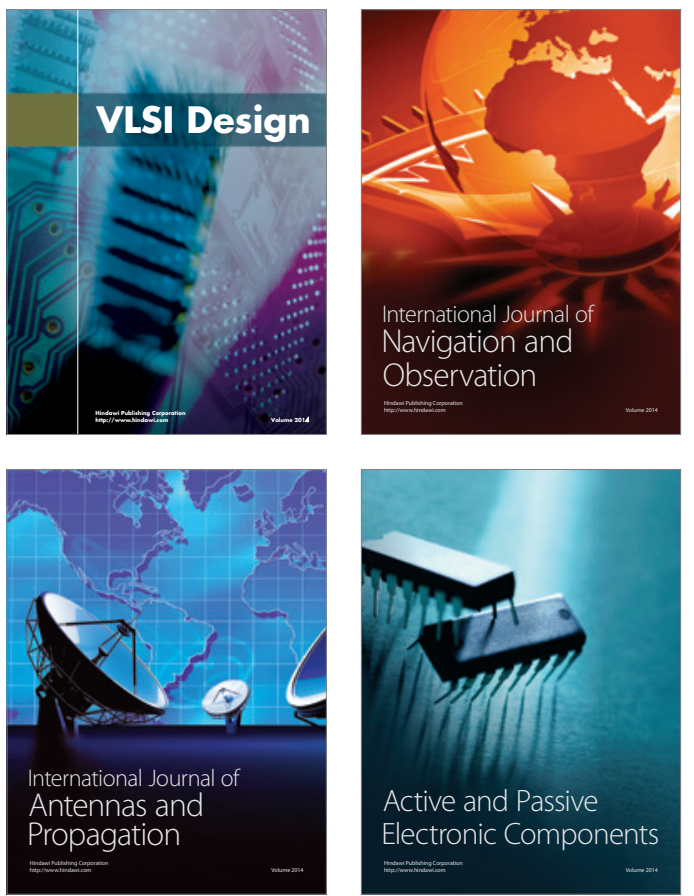
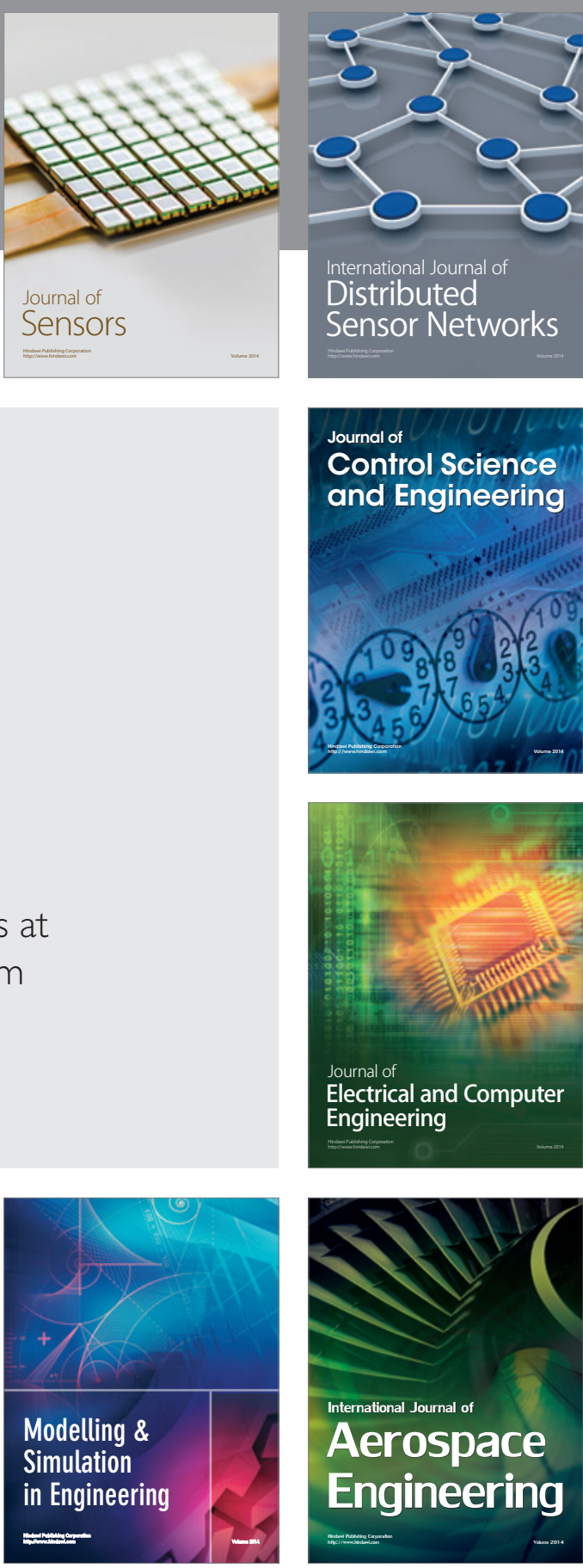

International Journal of

Distributed

Sensor Networks

Journal of

Control Science

and Engineering
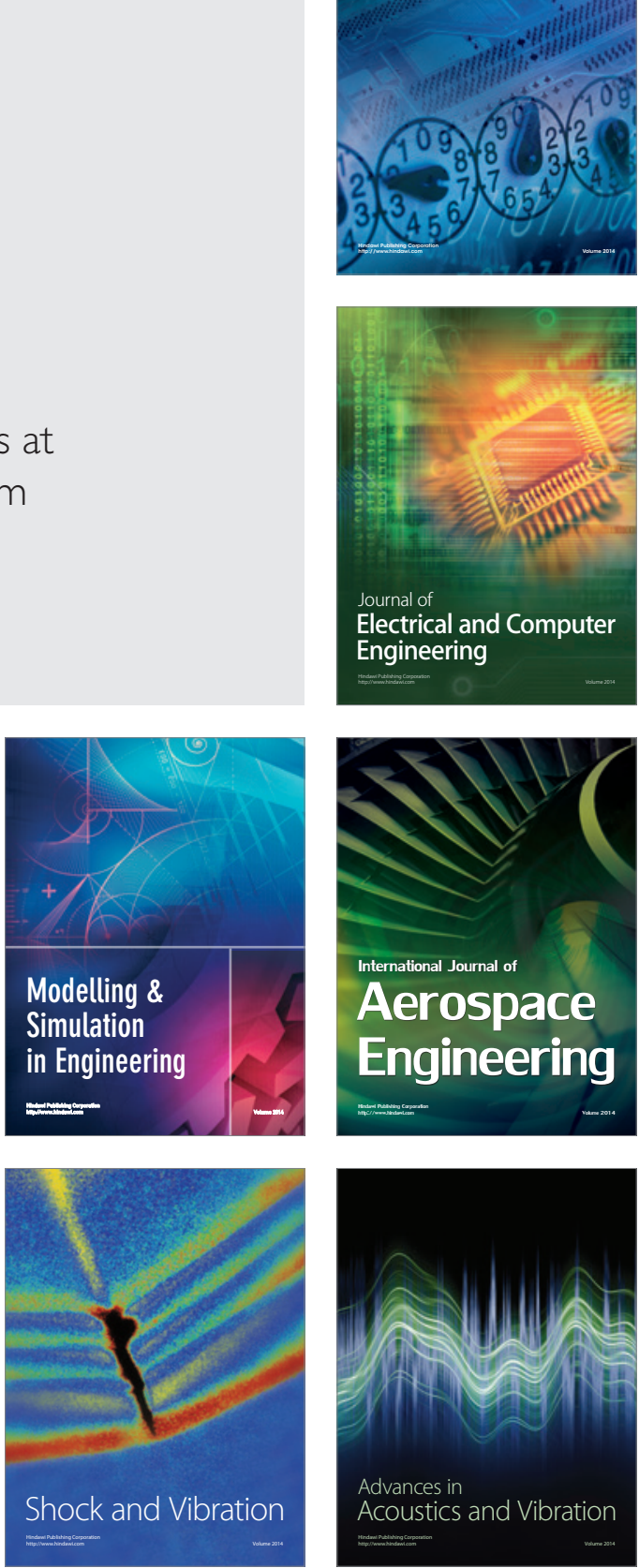